Article

\title{
Rapid Depletions of Subcutaneous Fat Mass and Skeletal Muscle Mass Predict Worse Survival in Patients with Hepatocellular Carcinoma Treated with Sorafenib
}

\author{
Kenji Imai *, Koji Takai, Takao Miwa, Daisuke Taguchi, Tatsunori Hanai, Atsushi Suetsugu, \\ Makoto Shiraki and Masahito Shimizu \\ Department of Gastroenterology/Internal Medicine, Gifu University Graduate School of Medicine, 1-1 Yanagido, \\ Gifu 501-1194, Japan \\ * Correspondence: ikenji@gifu-u.ac.jp; Tel.: +81-(58)-230-6308; Fax: +81-(58)-230-6310
}

Received: 9 July 2019; Accepted: 16 August 2019; Published: 19 August 2019

check for updates

\begin{abstract}
The aim of this study was to investigate whether rapid depletions of fat mass and skeletal muscle mass predict mortality in hepatocellular carcinoma (HCC) patients treated with sorafenib. This retrospective study evaluated $61 \mathrm{HCC}$ patients. The cross-sectional areas of visceral and subcutaneous fat mass and skeletal muscle mass were measured by computed tomography, from which the visceral fat mass index (VFMI), subcutaneous fat mass index (SFMI), and skeletal muscle index (L3SMI) were obtained. The relative changes in these indices per 120 days ( $\triangle$ VFMI, $\triangle$ SFMI, and $\Delta$ L3SMI) before and after sorafenib treatment were calculated in each patient. Patients within the 20th percentile cutoffs for these indices were classified into the rapid depletion (RD) group. Kaplan-Meier analysis revealed that with respect to $\Delta \mathrm{L} 3 \mathrm{SMI}(p=0.0101)$ and $\triangle$ SFMI $(p=0.0027)$, the RD group had a significantly poorer survival. Multivariate analysis using the Cox proportional-hazards model also demonstrated that $\triangle \mathrm{L} 3 \mathrm{SMI}$ ( $\leq-5.73$ vs. $>-5.73$; hazard ratio [HR]: $4.010,95 \%$ confidence interval [CI]: 1.799-8.938, $p=<0.001$ ) and $\Delta$ SFMI ( $\leq-5.33$ vs. $>-5.33$; HR: 4.109, 95\% CI: $1.967-8.584, p=<0.001$ ) were independent predictors. Rapid depletions of subcutaneous fat mass and skeletal muscle mass after the introduction of sorafenib indicate a poor prognosis.
\end{abstract}

Keywords: hepatocellular carcinoma; skeletal muscle; subcutaneous fat; sarcopenia; cancer cachexia; sorafenib

\section{Introduction}

Hepatocellular carcinoma (HCC) is one of the most common malignancies worldwide. Yearly, more than half a million people are diagnosed with HCC worldwide [1]. The prognosis of HCC is notably poor because only $46 \%$ of the patients are diagnosed at an early stage, and most do not receive curative therapy [2,3]. Furthermore, even those who undergo curative therapy are usually prone to recurrence because HCC generally develops in patients with liver cirrhosis, which is regarded as a hyper-carcinogenic disease [4]. In fact, the 5-year recurrence rate after curative treatment is more than $70 \%[5,6]$. Therefore, in addition to early detection and radical treatment for initial HCC, adequate therapy is critical to improve the prognosis of patients with this malignancy even when they are at an advanced stage.

Sorafenib is the first orally active multi-kinase inhibitor that has been confirmed to be efficacious against advanced HCC [7]. Sorafenib is first recommended in cases with Child-Pugh's A or B class and advanced stage [8-10], and is widely used currently to treat advanced HCC. The prognosis of patients with advanced HCC is significantly improved by sorafenib treatment $[7,11]$. However, several adverse 
events including hand-foot syndrome, fatigue, and rash can occur when using this agent. Digestive symptoms such as anorexia, nausea, and vomiting are also frequently observed in sorafenib-treated patients $[7,11]$. These adverse events cause malnutrition and unfavorable changes in body composition, which are involved in the worse survival of HCC patients [12]. Therefore, it is important to adequately deal with various nutritional challenges that arise during sorafenib treatment.

Skeletal muscle depletion or sarcopenia, which was initially defined as the loss of skeletal muscle mass that occurs with aging [13], has garnered attention as a new and promising prognostic factor for various malignancies, including HCC. For instance, skeletal muscle depletion assessed by computed tomography (CT) can predict a poor prognosis in all cancer stages [14] and in sorafenib-treated patients with HCC [15], with sarcopenia and rapid skeletal muscle wasting being associated with worse survival in those with liver cirrhosis [16,17].

In addition to skeletal muscle mass, fat mass has a notable impact on the prognosis of HCC patients. High subcutaneous fat mass (SFM) volume is involved in better survival outcomes in HCC patients treated with transcatheter intra-arterial therapy [18]. Compared to low visceral fat mass (VFM) volume, high VFM volume is advantageous for long-term survival after hepatic resection of HCC [19]. High VFM without skeletal muscle mass loss is also associated with a better prognosis in HCC patients treated with sorafenib [20]. However, high VFM is a predictor of poor survival in patients with HCC treated with tyrosine kinase inhibitors, including sorafenib [21]. Excessive VFM accumulation plays a critical role in obesity-related liver carcinogenesis [22]. In addition, it is unclear whether fat mass wasting after sorafenib introduction has effects on the outcomes of HCC patients.

The purpose of this study was thus to evaluate the effect of the changes in body composition, including skeletal muscle, SFM, and VFM after sorafenib introduction on the prognosis of patients with advanced HCC.

\section{Results}

\subsection{Comparison of Baseline Characteristics and Laboratory Data of The Sorafenib-Treated HCC Patients with} and without Sarcopenia

The baseline characteristics and laboratory data of the 61 patients (54 men and 7 women, average age 67.3 years) just before the introduction of sorafenib and the comparison of the groups with $(n=25)$ and without sarcopenia $(n=36)$ are shown in Table 1 . The sarcopenia group had significantly lower values than the non-sarcopenia group regarding body composition parameters for body mass index $\left(\mathrm{kg} / \mathrm{m}^{2}, 20.1\right.$ vs. $\left.23.9, p<0.001\right)$, skeletal muscle index (L3SMI $\left[\mathrm{cm}^{2} / \mathrm{m}^{2}\right], 37.5$ vs. 48.5, $\left.p<0.001\right), \mathrm{SFM}$ index (SFMI [ $\mathrm{cm}^{2} / \mathrm{m}^{2}$ ], 22.1 vs. 43.8, $p<0.001$ ), and VFM index (VFMI [ $\left.\mathrm{cm}^{2} / \mathrm{m}^{2}\right], 25.5$ vs. 44.3, $p<0.001$ ). The administration period of sorafenib was also significantly shorter in the sarcopenia group than in the non-sarcopenia group (days; 325 vs. 544, $p=0.032$ ). The mean interval of CT examination was 127.6 days. The mean values of $\triangle \mathrm{L} 3 \mathrm{SMI}, \triangle \mathrm{SFMI}$, and $\triangle \mathrm{VFMI}$ during almost the same period of the scan interval (120 days) were $-1.70,-0.46$, and $1.02\left(\mathrm{~cm}^{2} / \mathrm{m}^{2} / 120\right.$ days), respectively. There were no significant differences in the values of $\triangle$ L3SMI, $\triangle$ SFMI, and $\triangle$ VFMI between the two groups. 
Table 1. Baseline demographic and clinical characteristics of patients with and without sarcopenia.

\begin{tabular}{|c|c|c|c|c|c|}
\hline \multicolumn{2}{|c|}{ Variables } & $\begin{array}{l}\text { All Cases } \\
(n=61)\end{array}$ & $\begin{array}{l}\text { Non-Sarcopenia } \\
\quad(n=36)\end{array}$ & $\begin{array}{l}\text { Sarcopenia } \\
(n=25)\end{array}$ & $p$-Value \\
\hline \multicolumn{2}{|c|}{ Sex (male/female) } & $54 / 7$ & $32 / 4$ & $22 / 3$ & $>0.999$ \\
\hline \multicolumn{2}{|c|}{ Age (years) } & $67.3 \pm 11.5$ & $67.1 \pm 11.7$ & $67.7 \pm 11.3$ & 0.826 \\
\hline \multicolumn{2}{|c|}{ Etiology (B/C/others) } & $14 / 28 / 19$ & $6 / 17 / 13$ & $8 / 11 / 6$ & 0.504 \\
\hline \multicolumn{2}{|c|}{ Child-Pugh score $(5 / 6)$} & $43 / 18$ & $27 / 9$ & $16 / 9$ & 0.401 \\
\hline \multicolumn{2}{|c|}{ Stage (III/IVA/IVB) } & $20 / 13 / 28$ & $11 / 10 / 15$ & $9 / 3 / 13$ & 0.348 \\
\hline \multicolumn{2}{|c|}{ Combination therapy (yes/no) } & $42 / 19$ & $24 / 12$ & $18 / 7$ & 0.781 \\
\hline \multicolumn{2}{|c|}{ BMI $\left(\mathrm{kg} / \mathrm{m}^{2}\right)$} & $22.3 \pm 3.0$ & $23.9 \pm 2.4$ & $20.1 \pm 2.4$ & $<0.001$ \\
\hline \multirow{3}{*}{ L3SMI $\left(\mathrm{cm}^{2} / \mathrm{m}^{2}\right)$} & All & $44.0 \pm 7.7$ & $48.5 \pm 6.1$ & $37.5 \pm 4.6$ & $<0.001$ \\
\hline & Male & $44.5 \pm 7.7$ & $48.9 \pm 6.2$ & $38.2 \pm 4.4$ & $<0.001$ \\
\hline & Female & $39.9 \pm 7.4$ & $45.2 \pm 4.3$ & $32.7 \pm 2.3$ & 0.006 \\
\hline & All & $34.9 \pm 22.0$ & $43.8 \pm 21.9$ & $22.1 \pm 14.8$ & $<0.001$ \\
\hline \multirow[t]{3}{*}{ SFMI $\left(\mathrm{cm}^{2} / \mathrm{m}^{2}\right)$} & Male & $31.5 \pm 18.9$ & $39.5 \pm 17.8$ & $19.9 \pm 13.7$ & $<0.001$ \\
\hline & Female & $61.2 \pm 28.1$ & $78.0 \pm 24.0$ & $38.8 \pm 4.6$ & 0.054 \\
\hline & All & $36.6 \pm 21.0$ & $44.3 \pm 20.5$ & $25.5 \pm 16.4$ & $<0.001$ \\
\hline \multirow[t]{2}{*}{$\operatorname{VFMI}\left(\mathrm{cm}^{2} / \mathrm{m}^{2}\right)$} & Male & $31.5 \pm 18.4$ & $44.9 \pm 20.7$ & $26.1 \pm 17.2$ & $<0.001$ \\
\hline & Female & $37.2 \pm 21.4$ & $39.4 \pm 20.9$ & $21.0 \pm 8.2$ & 0.217 \\
\hline \multicolumn{2}{|c|}{$\Delta \operatorname{LSSMI}\left(\mathrm{cm}^{2} / \mathrm{m}^{2} / 120\right.$ days $)$} & $-1.70 \pm 7.96$ & $-2.14 \pm 4.82$ & $-1.07 \pm 11.13$ & 0.609 \\
\hline \multicolumn{2}{|c|}{$\Delta$ SFMI $\left(\mathrm{cm}^{2} / \mathrm{m}^{2} / 120\right.$ days $)$} & $-0.46 \pm 11.34$ & $0.35 \pm 13.17$ & $-1.62 \pm 8.12$ & 0.509 \\
\hline \multicolumn{2}{|c|}{$\Delta$ VFMI $\left(\mathrm{cm}^{2} / \mathrm{m}^{2} / 120\right.$ days $)$} & $1.02 \pm 12.11$ & $0.72 \pm 13.96$ & $1.44 \pm 9.08$ & 0.821 \\
\hline \multicolumn{2}{|c|}{ CT examination interval (days) } & $127.6 \pm 89.5$ & $127.0 \pm 62.9$ & $128.5 \pm 119.4$ & 0.949 \\
\hline \multicolumn{2}{|c|}{ Administration period of sorafenib (days) } & $455 \pm 396$ & $544 \pm 448$ & $325 \pm 264$ & 0.032 \\
\hline \multicolumn{2}{|c|}{ Therapeutic effect (CR/PR/SD/PD) } & $3 / 34 / 5 / 19$ & $2 / 18 / 2 / 14$ & $1 / 16 / 3 / 5$ & 0.368 \\
\hline
\end{tabular}

Values are presented as mean \pm standard deviation. Sarcopenia was defined as an L3SMI value of $\leq 38.0 \mathrm{~cm}^{2} / \mathrm{m}^{2}$ for women and $\leq 42.0 \mathrm{~cm}^{2} / \mathrm{m}^{2}$ for men. B, hepatitis B virus; C, hepatitis C virus; BMI, body mass index; L3SMI, third lumbar vertebra skeletal muscle index; SFMI, subcutaneous fat mass index; VFMI, visceral fat mass index; CR, complete response; $\mathrm{PR}$, partial response; $\mathrm{SD}$, stable disease; $\mathrm{PD}$, progressive disease.

\subsection{Impact of Sarcopenia and the Changes in Body Composition on Overall Survival in the Patients with HCC} Treated with Sorafenib

The 1-, 3-, and 5-year overall survival rates were 58.9, 27.2, and 10.9\%, respectively, for those with sarcopenia, and 77.3, 43.8, and $29.2 \%$ respectively, for those without sarcopenia, indicating that those with sarcopenia had a significantly poorer survival than those without sarcopenia $(p=0.0157$, Figure 1a).

Next, we examined the impact of the rapid depletion of skeletal muscle mass and fat mass on the survival of the HCC patients treated with sorafenib. Patients within the 20th percentile cutoffs for $\triangle \mathrm{L} 3 \mathrm{SMI}(-5.73), \triangle \mathrm{SFMI}(-5.33)$, and $\triangle$ VFMI (-3.95) were classified into a rapid depletion (RD) group; those who did not meet the 20th percentile cutoffs were classified into a non-RD group. There were no significant differences in the prevalence of patients with RD of $\Delta$ L3SMI $(p>0.999), \Delta$ SFMI $(p=0.526)$, and $\triangle$ VFMI $(p=0.099)$ between the sarcopenia and non-sarcopenia groups (Table S1). We then compared the overall survival between these two groups. Regarding $\Delta$ L3SMI $(p=0.0101$, Figure $1 b$ ) and $\triangle$ SFMI ( $p=0.0027$, Figure $1 c)$, the RD group experienced a significantly poorer survival than non-RD group, whereas for $\triangle$ VFMI ( $p=0.453$, Figure $1 d)$, survival was comparable between both groups. Therefore, the rapid depletion of skeletal muscle mass and, especially, SFM predicts the survival of the sorafenib-treated HCC patients. We also examined the above analyses by gender. Male patients with sarcopenia $(p=0.025)$ and RD of $\Delta$ L3SMI $(p=0.003)$ and $\triangle$ SFMI $(p=0.007)$ had poorer survival (Figure S1). Female patients with RD in $\triangle$ SFMI $(p=0.014$ ) had poorer survival (Figure S2).

We then classified the enrolled patients into four groups according to the cutoffs for $\Delta \mathrm{L} 3 \mathrm{SMI}$ and $\Delta$ SFMI as described above; type I: Rapid depletion seen in neither $\Delta$ L3SMI nor $\Delta$ SFMI $(n=39)$, type II: Rapid depletion seen in $\Delta$ L3SMI alone $(n=10)$, type III: Rapid depletion seen in $\Delta$ SFMI alone $(n=10)$, and type IV: Rapid depletion seen in both $\triangle$ L3SMI and $\triangle$ SFMI $(n=2)$. The patients classified into type I had a significantly better survival than both type II ( $p=0.007)$ and type III $(p=0.009$; Figure 2). 
(a)

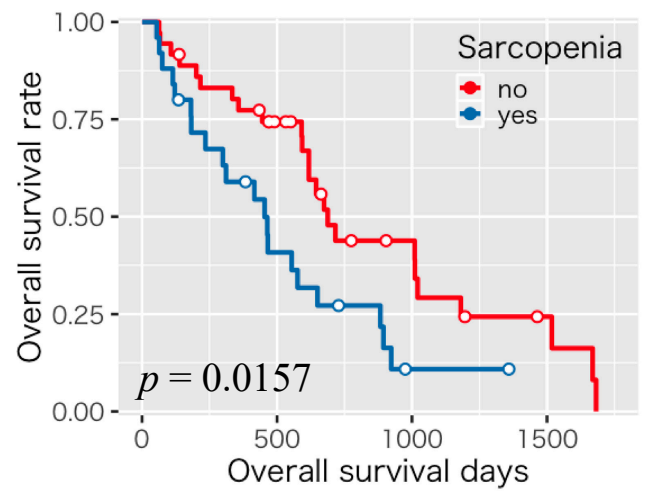

$\begin{array}{lcccc}\text { no } & 36 & 22 & 9 & 3 \\ \text { yes } & 25 & 9 & 1 & 0\end{array}$

(c)

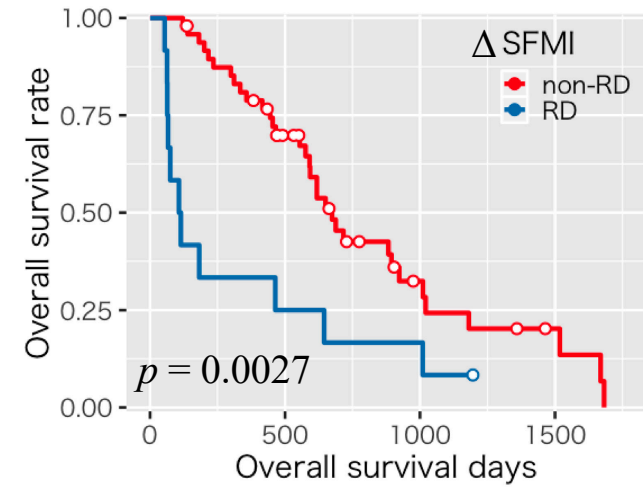

(b)

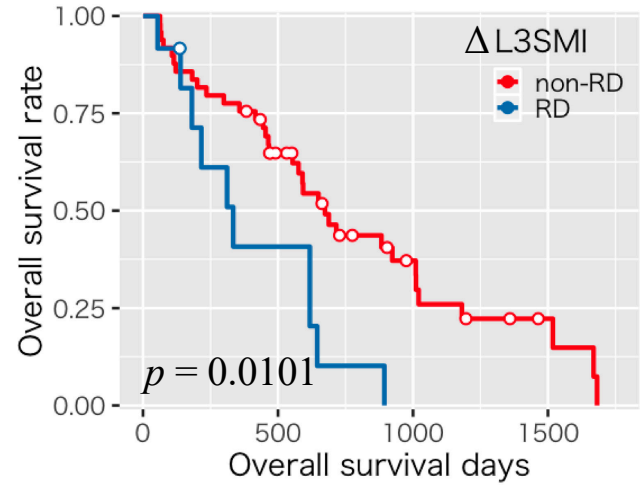

$\begin{array}{lcccc}\text { non- } & 49 & 27 & 10 & 3 \\ \text { RD } & 12 & 4 & 0 & 0\end{array}$

(d)

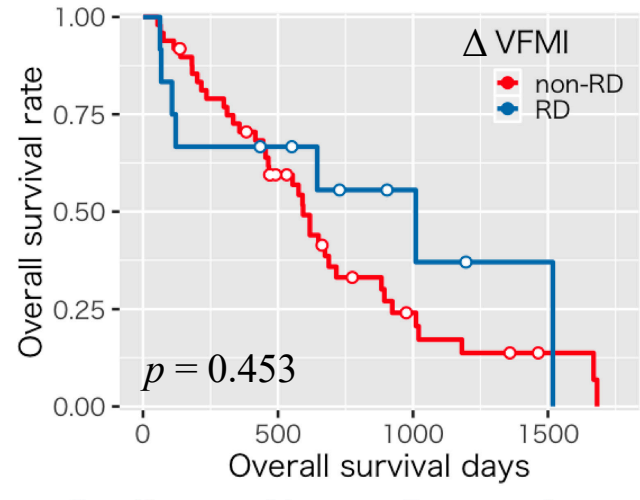

$\begin{array}{lllll}\text { non-R } & 49 & 24 & 7 & 2 \\ \mathrm{RD} & 12 & 7 & 3\end{array}$

Figure 1. Kaplan-Meier curves for overall survival time divided into the presence or absence of sarcopenia (a) and rapid depletion (RD) or non-rapid depletion (non-RD) groups in $\triangle \mathrm{L} 3 \mathrm{SMI}(\leq-5.73$ and $>-5.73 \mathrm{~cm}^{2} / \mathrm{m}^{2} / 120$ days) (b), $\Delta$ SFMI ( $\leq-5.33$ and $>-5.33 \mathrm{~cm}^{2} / \mathrm{m}^{2} / 120$ days) (c), and $\Delta$ VFMI $(\leq-3.95$ and $>-3.95 \mathrm{~cm}^{2} / \mathrm{m}^{2} / 120$ days) (d).

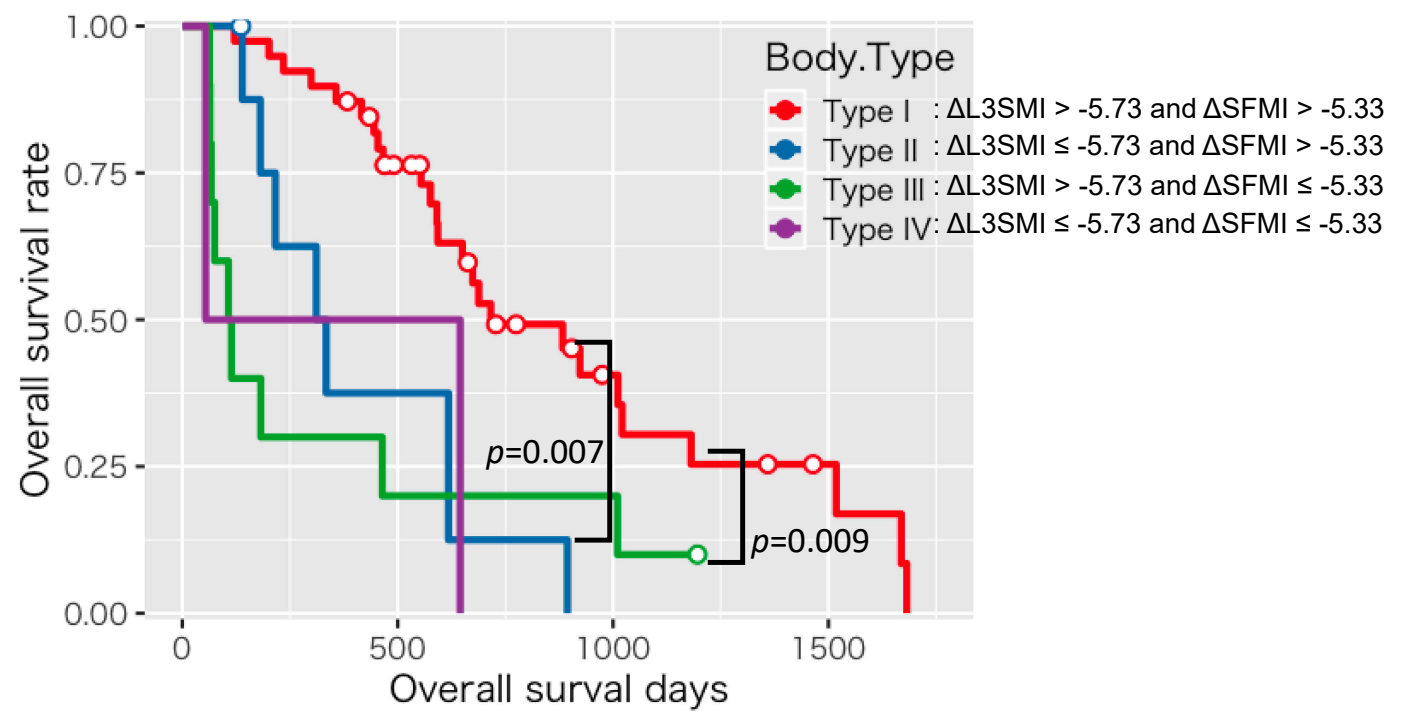

$\begin{array}{ccccc}\text { Type I } & 39 & 25 & 8 & 3 \\ \text { Type II } & 10 & 3 & 0 & 0 \\ \text { Type III } & 10 & 2 & 2 & 0 \\ \text { Type IV } & 2 & 1 & 0 & 0\end{array}$

Figure 2. Kaplan-Meier curves for overall survival time divided into four groups according to the cutoffs for $\Delta$ L3SMI $\left(-5.73 \mathrm{~cm}^{2} / \mathrm{m}^{2} / 120\right.$ days) and $\Delta$ SFMI $\left(-5.33 \mathrm{~cm}^{2} / \mathrm{m}^{2} / 120\right.$ days). 
Subsequently, we aimed to determine possible prognostic factors for the enrolled patients using the Cox proportional-hazards model. Multivariate analysis demonstrated that the presence of sarcopenia (yes vs. no; hazard ratio [HR]: $2.453,95 \%$ confidence interval [CI]: 1.273-4.728, $p=0.007$ ), $\Delta$ L3SMI ( $\leq-5.73$ vs. $>-5.73$; HR: $4.010,95 \%$ CI: $1.799-8.938, p=<0.001), \Delta$ SFMI $(\leq-5.33$ vs. $>-5.33$; HR: $4.109,95 \%$ CI: $1.967-8.584, p=<0.001$ ), and therapeutic effect (progressive disease vs. complete response/partial response/stable disease; HR: 4.603, 95\% CI: 2.188-9.683, $p=<0.001$ ) were independent predictors of survival for the HCC patients treated with sorafenib (Table 2).

Table 2. Univariate and multivariate analyses of possible prognostic factors in patients with hepatocellular carcinoma treated sorafenib, according to the Cox proportional-hazards model.

\begin{tabular}{|c|c|c|c|c|}
\hline \multirow{2}{*}{ Variables } & \multicolumn{2}{|c|}{ Univariate Analysis } & \multicolumn{2}{|c|}{ Multivariate Analysis } \\
\hline & HR (95\% CI) & $p$-Value & HR $(95 \%$ CI) & $p$-Value \\
\hline Sex (male vs. female) & $0.872(0.365-2.082)$ & 0.758 & & \\
\hline Age (years) & $0.980(0.956-1.006)$ & 0.127 & & \\
\hline $\begin{array}{l}\text { Child-Pugh score } \\
\text { (6 vs. } 5)\end{array}$ & $1.630(0.850-3.154)$ & 0.141 & & \\
\hline Stage (III vs. IV) & 1.009 (0.526-1.935) & 0.979 & & \\
\hline $\begin{array}{l}\text { Combination therapy } \\
\text { (yes vs. no) }\end{array}$ & 1.007 (0.508-1.995) & 0.984 & & \\
\hline BMI $\left(\mathrm{kg} / \mathrm{m}^{2}\right)$ & $0.954(0.846-1.075)$ & 0.440 & & \\
\hline Sarcopenia (yes vs. no) & $2.124(1.137-3.967)$ & 0.018 & $2.453(1.273-4.728)$ & 0.007 \\
\hline $\begin{array}{c}\Delta \text { L3SMI } \\
(\leq-5.73 \text { vs. }>-5.73)\end{array}$ & $2.560(1.218-5.377)$ & 0.013 & $4.010(1.799-8.938)$ & $<0.001$ \\
\hline $\begin{array}{c}\Delta \text { SFMI } \\
(\leq-5.33 \text { vs. }>-5.33)\end{array}$ & $2.771(1.382-5.559)$ & 0.004 & 4.109 (1.967-8.584) & $<0.001$ \\
\hline $\begin{array}{c}\Delta \text { VFMI } \\
(\leq-3.95 \text { vs. }>-3.95)\end{array}$ & $0.733(0.324-1.657)$ & 0.456 & & \\
\hline $\begin{array}{l}\text { Therapeutic effect } \\
\text { (PD vs. CR/PR/SD) }\end{array}$ & 3.049 (1.563-5.949) & 0.001 & $4.603(2.188-9.683)$ & $<0.001$ \\
\hline
\end{tabular}

HR, hazard ratio; CI, confidence interval; $\mathrm{BMI}$, body mass index; $\Delta$ L3SMI, change in third lumbar vertebra skeletal muscle index; $\triangle \mathrm{SFMI}$, change in subcutaneous fat mass index; $\triangle$ VFMI, change in visceral fat mass index; $C R$, complete response; $\mathrm{PR}$, partial response; $\mathrm{SD}$, stable disease; $\mathrm{PD}$, progressive disease.

\section{Discussion}

Sarcopenia is associated with poor outcomes in patients with HCC $[14,15]$. Skeletal muscle in HCC patients decreases according to worsening liver functional reserve and larger tumor size [23]. In this study, $41 \%$ of the enrolled patients were already sarcopenic when they started sorafenib treatment, suggesting that sorafenib might often be used in HCC patients with sarcopenia. The results of this study revealed that sarcopenia is an independent predictive factor of survival in HCC patients treated with sorafenib, which is consistent with the results of a previous report [15]. Because the presence of sarcopenia was associated with a shorter administration period of sorafenib, sorafenib might not have been sufficiently administered to sarcopenic patients in the present study. Moreover, rapid skeletal muscle wasting after introducing sorafenib predicts worse survival in patients with HCC. Patients with rapid depletion of skeletal muscle mass are considered to already be sarcopenic or expected to experience sarcopenia in the near future. Therefore, adequate measures for sarcopenia are required before HCC reaches an advanced stage, and even before HCC emerges. Furthermore, there is a possibility that sorafenib itself inhibits muscle protein synthesis directly [24], indicating that HCC patients treated with sorafenib are prone to sarcopenia. In order to improve the prognosis of HCC patients, it is necessary to pay more attention to skeletal muscle depletion during sorafenib treatment.

In addition to sarcopenia, patients with advanced malignancies frequently experience malnutrition and cachexia, both of which show total body weight loss, adipose tissue depression, and muscle atrophy [25-27]. To the best of our knowledge, this is the first study demonstrating that the rapid depletion of SFM is an independent prognostic factor in the patients with advanced HCC treated with 
sorafenib. Although the definition of cachexia does not necessarily require the depletion of SFM, SFM depletion is often observed in cachectic patients $[26,28,29]$. It has been reported that subcutaneous adipose tissue is beneficial for lipid and glucose metabolism [30]. Adipose tissue works as an energy storage and is thus able to protect cancer patients against increased energy exhaustion induced by cachexia [31]. Therefore, regarding HCC patients with rapid SFM depletion, it should be considered that they suffer from malnutrition and, in that case, it is crucial to correct the negative energy balance that led to the malnutrition. In the present study, compared to the patients without rapid depletion of both skeletal muscle mass and SFM, those with either rapid depletion of skeletal muscle mass or SFM showed a significantly worse prognosis. Loss of skeletal muscle is regarded as one of the diagnostic criteria with regard to the definitions of both cancer cachexia and sarcopenia, but SFM is not [27,32]. Therefore, considering these definitions, those with SFM alone, who have a poor prognosis, could be overlooked. Evaluation of both skeletal muscle mass and SFM throughout the period of HCC treatment is important to improve the prognosis and quality of life of the patients.

In order to manage cancer cachexia and sarcopenia adequately, it is critical to diagnose and treat these conditions before they reach a refractory stage at which interventions are ineffective [33]. Anorexia and malnutrition are significantly associated with the reduction or discontinuation of sorafenib [7], which leads to a poor prognosis in HCC. If the depletion of skeletal muscle and/or SFM is observed, effective nutritional interventions should be administered.

In the present study, rapid depletion of VFM was not associated with prognosis in HCC patients treated with sorafenib. Currently, it is unclear whether the accumulation of VFM is beneficial or harmful with respect to the prognosis of patients with HCC [19-21]. However, it should be considered that overnutrition and the accumulation of visceral adipose tissue are involved in liver carcinogenesis [22]. There is a significant relationship between the risk of HCC recurrence after curative treatment and various obesity-related disorders such as insulin resistance, oxidative stress, and hyperleptinemia [34-37]. Excessive accumulation of VFM, which is associated with hepatic inflammation [38], is an independent risk factor for HCC recurrence after curative treatment [39]. Therefore, maintaining the ideal body composition including both skeletal muscle mass and fat mass is required for patients with chronic liver disease.

This study has several limitations. First, it was a retrospective, single-center study, and the sample size was comparatively small. Thus, a prospective study involving a larger number of patients should be performed to validate the findings of the present study. Second, because of the retrospective design of our study, muscle strength, including grip strength and walking speed, which is usually regarded as a diagnostic criterion for sarcopenia [32], was not assessed. Third, we used arbitrary cutoff values for $\triangle \mathrm{L} 3 \mathrm{SMI}$ and $\triangle$ SFMI that were determined based on only the 20th percentiles of these variables, although these cutoff values were notably useful in screening the poor prognosis group. It is important to avoid overlooking such groups because of inappropriate cut-offs. Therefore, further long-term prospective studies including a larger number of patients are also needed to determination of the optimal cut-offs of these variables. Fourth, inter-observer reproducibility was not evaluated in this study because there was only one in our institution who could measure these parameters. However, we think it should be so excellent as intra-observer reproducibility because the areas of skeletal muscle mass and fat were almost automatically calculated by the SYNAPSE VINCENT software.

\section{Materials and Methods}

\subsection{Patients, Treatment, and Follow-up Strategy}

The patient selection in this study is shown in Figure 3. Among the 76 patients treated with sorafenib for advanced HCC in our hospital between May 2009 and December 2017, 11 were excluded because they did not take the agent for more than a month and 4 were excluded because they did not undergo abdominal CT before and after the introduction of sorafenib. The remaining 61 patients were enrolled in this study. 
The objective of the sorafenib introduction was determined according to the Clinical Practice Guidelines for HCC issued by the Japan Society of Hepatology (JSH) [40]. When introducing sorafenib, all the patients in this study received explanations from their attending doctor, pharmacist, and nurse about how to take this drug, which complications (including appetite loss) could occur, and how to prevent and treat complications by using a handbook the drug manufacturer (Bayer HealthCare Pharmaceuticals, Berlin, Germany) published for patients treated with sorafenib. In particular, to prevent appetite loss, the patients were advised to eat freely and drink enough water. However, if appetite loss occurred, they were advised to feel free to consult medical stuff. When patients lost their appetite or showed signs of malnutrition such as hypoalbuminemia, branched-chain amino acids or other dietary supplement and antiemetic were prescribed as needed. Patients were thereafter followed on an outpatient basis and underwent dynamic CT, magnetic resonance imaging, or ultrasound every 3 months. Each patient's therapeutic response was judged according to the Response Evaluation Criteria in Cancer of the Liver [41], which is an appropriate system for the assessment of the post-therapeutic response of HCC to sorafenib [42]. Overall survival was defined as the interval from the date of sorafenib introduction to the date of death or December 2018 for surviving patients. All study participants provided verbal informed consent, which was considered sufficient because this study followed an observational research design that did not require new human biological specimens. The study design, including this consent procedure, was approved by the ethics committee of the Gifu University School of Medicine (ethical protocol code: 29-26).

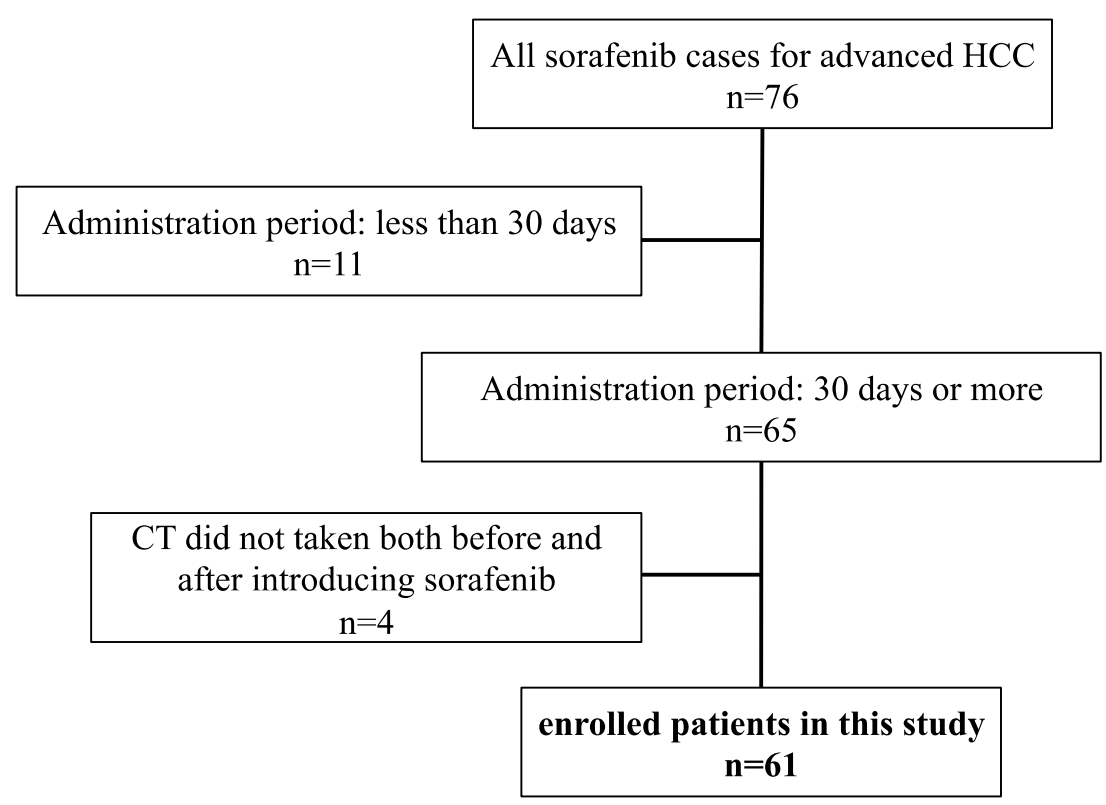

Figure 3. Patient flow in this study.

\subsection{Image Analysis of Skeletal Muscle Mass and Subcutaneous and Visceral Fat Mass}

Skeletal muscle mass, SFM, and VFM were measured using an enhanced CT image (Discovery CT 750 HD, Revolution CT; GE Healthcare, Milwaukee, WI, USA) that had been taken solely for the purpose of diagnosing HCC prior to introducing sorafenib in Gifu University Hospital. The CT imaging conditions in this study were as follows; the tube voltage was $120 \mathrm{kV}$, slice thickness was $5 \mathrm{~mm}$, air calibration scans were performed every day, and water phantom calibration by the manufacturer was performed every 3 months. A transverse CT image at the third lumbar vertebra (L3) in the inferior direction was assessed. The muscles in the L3 region were analyzed using SYNAPSE VINCENT software (Fujifilm Medical, Tokyo, Japan), which enables specific tissue demarcation using Hounsfield unit (HU) thresholds. The muscles were quantified within a range of -29 to $+150 \mathrm{HU}$ [43], and tissue boundaries were manually corrected as needed. The cross-sectional areas of the muscle $\left(\mathrm{cm}^{2}\right)$ at the L3 
level computed from each image were normalized by the square of the height $\left(\mathrm{m}^{2}\right)$ to obtain the L3 skeletal muscle index (L3SMI, $\mathrm{cm}^{2} / \mathrm{m}^{2}$ ). Sarcopenia was defined as an L3SMI value $\leq 38.0 \mathrm{~cm}^{2} / \mathrm{m}^{2}$ for women and $\leq 42.0 \mathrm{~cm}^{2} / \mathrm{m}^{2}$ for men, according to JSH guidelines for sarcopenia [32]. In the same manner, the cross-sectional areas of SFM and VFM $\left(\mathrm{cm}^{2}\right)$ at the umbilical point were measured using a built-in function in the SYNAPSE VINCENT software. These values were then normalized by the square of the height $\left(\mathrm{m}^{2}\right.$ ) to obtain the SFM index (SFMI, $\mathrm{cm}^{2} / \mathrm{m}^{2}$ ) and VFM index (VFMI, $\mathrm{cm}^{2} / \mathrm{m}^{2}$ ). One trained physician (K.I.) measured these parameters. To evaluate intra-observer reproducibility, the physician measured 30 cases of randomly selected data two times at least 3 months apart. The intra-observer reproducibilities of L3SMI, SFMI, and VFMI were excellent with intraclass correlation coefficients for all these parameters, exceeding 0.99 (Figure S3). The CT level at the umbilical point, which is most appropriate for evaluating the volume of adipose tissue [44], was used to calculate both SFMI and VFMI.

The differences in L3SMI, SFMI, and VFMI between post- and pre-sorafenib introduction were divided by $C$ T examination interval to obtain $\Delta$ L3SMI, $\Delta$ SFMI, and $\Delta$ VFMI $\left(\mathrm{cm}^{2} / \mathrm{m}^{2} / 120\right.$ days), respectively. The outline and formula of $\Delta \mathrm{L} 3 \mathrm{SMI}, \Delta$ SFMI, and $\Delta$ VFMI are shown in Figure 4.

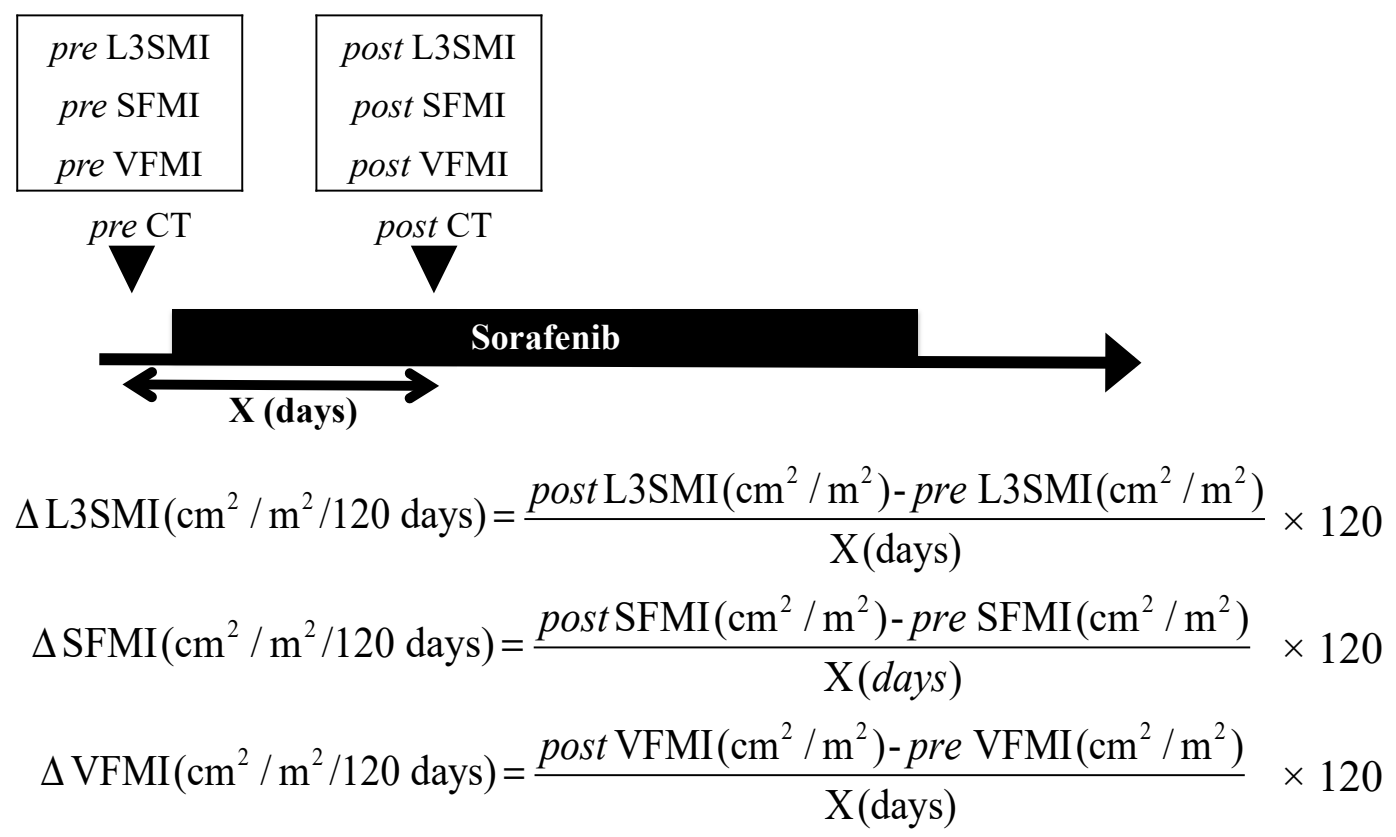

Figure 4. Outline and formula for $\triangle \mathrm{L} 3 \mathrm{SMI}, \triangle \mathrm{SFMI}$, and $\triangle$ VFMI. L3 skeletal muscle index (L3SMI) was the cross-sectional area of the muscle $\left(\mathrm{cm}^{2}\right)$ at the L3 level of the computed tomography (CT) image normalized by the square of the height $\left(\mathrm{m}^{2}\right)$. Subcutaneous fat mass index (SFMI) and visceral fat mass index (VFMI) were the cross-sectional areas of the subcutaneous and visceral fat $\left(\mathrm{cm}^{2}\right)$, respectively, at the umbilical point normalized by the square of the height $\left(\mathrm{m}^{2}\right)$.

\subsection{Statistical Analysis}

Baseline characteristics were compared using the Student's $t$-test for continuous variables or the $\chi^{2}$ test for categorical variables. Overall survival was estimated using the Kaplan-Meier method. Differences between curves were evaluated using the log-rank test, and when there were more than three curves, Holm correction was used to counteract the problem of multiple comparisons. The Cox proportional-hazards model was used to analyze which factors, including $\triangle \mathrm{L} 3 \mathrm{SMI}, \triangle \mathrm{SFMI}$, and $\Delta$ VFMI, affected overall survival. Statistical significance was defined as $p<0.05$. All statistical analyses were performed using $R$ ver. 3.3.1 (R Foundation for Statistical Computing, Vienna, Austria; http://www.R-project.org/). 


\section{Conclusions}

Sarcopenia and rapid depletions of SFM and skeletal muscle mass after sorafenib introduction were associated with a poor survival in patients with advanced HCC. Adequate treatments for underlying liver diseases, especially nutritional intervention, should be conducted to avoid these unfavorable changes in body composition, which could help improve the prognosis of HCC patients treated with sorafenib.

Supplementary Materials: The following are available online at http:/www.mdpi.com/2072-6694/11/8/1206/s1, Figure S1: Kaplan-Meier curves for overall survival time for male, Figure S2: Kaplan-Meier curves for overall survival time for female, Figure S3: Intra-observer validations, Table S1: The prevalence of patients with RD of $\triangle \mathrm{L} 3 \mathrm{SMI}, \triangle \mathrm{SFMI}$, and $\triangle$ VFMI between sarcopenia and non-sarcopenia groups.

Author Contributions: Conceptualization, formal analysis, and writing-original draft preparation, K.I.; investigation, K.T., T.M., D.T., T.H., A.S., and M.S. (Makoto Shiraki); writing-review and editing, M.S. (Masahito Shimizu); supervision, K.T.

Funding: This research received no external funding.

Conflicts of Interest: The authors declare no conflicts of interest.

\section{References}

1. El-Serag, H.B. Hepatocellular carcinoma. N. Engl. J. Med. 2011, 365, 1118-1127. [CrossRef] [PubMed]

2. Njei, B.; Rotman, Y.; Ditah, I.; Lim, J.K. Emerging trends in hepatocellular carcinoma incidence and mortality. Hepatology 2015, 61, 191-199. [CrossRef] [PubMed]

3. Singal, A.G.; El-Serag, H.B. Hepatocellular Carcinoma from Epidemiology to Prevention: Translating Knowledge into Practice. Clin. Gastroenterol. Hepatol. 2015, 13, 2140-2151. [CrossRef]

4. El-Serag, H.B. Hepatocellular carcinoma: An epidemiologic view. J. Clin. Gastroenterol. 2002, 35, S72-S78. [CrossRef]

5. Poon, R.T. Prevention of recurrence after resection of hepatocellular carcinoma: A daunting challenge. Hepatology 2011, 54, 757-759. [CrossRef] [PubMed]

6. Shiina, S.; Tateishi, R.; Arano, T.; Uchino, K.; Enooku, K.; Nakagawa, H.; Asaoka, Y.; Sato, T.; Masuzaki, R.; Kondo, Y.; et al. Radiofrequency ablation for hepatocellular carcinoma: 10-year outcome and prognostic factors. Am. J. Gastroenterol. 2012, 107, 569-577. [CrossRef] [PubMed]

7. Llovet, J.M.; Ricci, S.; Mazzaferro, V.; Hilgard, P.; Gane, E.; Blanc, J.F.; de Oliveira, A.C.; Santoro, A.; Raoul, J.L.; Forner, A.; et al. Sorafenib in advanced hepatocellular carcinoma. N. Engl. J. Med. 2008, 359, 378-390. [CrossRef] [PubMed]

8. Galle, P.R.; Forner, A.; Llovet, J.M.; Mazzaferro, V.; Piscaglia, F.; Raoul, J.L.; Schirmacher, P.; Vilgrain, V. EASL Clinical Practice Guidelines: Management of hepatocellular carcinoma. J. Hepatol. 2018, 69, 182-236. [CrossRef] [PubMed]

9. Fukuda, T.; Ku, Y.; Kaneko, S.; Okazaki, M.; Matsuyama, Y.; Igaki, H.; Kawasaki, S.; Tateishi, R.; Akahane, M.; Kudo, M.; et al. Evidence-based Clinical Practice Guidelines for Hepatocellular Carcinoma: The Japan Society of Hepatology 2013 update (3rd JSH-HCC Guidelines). Hepatol. Res. 2015, 45. [CrossRef]

10. Bruix, J.; Sherman, M. American Association for the Study of Liver Diseases Management of hepatocellular carcinoma: An update. Hepatology 2011, 53, 1020-1022. [CrossRef]

11. Cheng, A.L.; Kang, Y.K.; Chen, Z.; Tsao, C.J.; Qin, S.; Kim, J.S.; Luo, R.; Feng, J.; Ye, S.; Yang, T.S.; et al. Efficacy and safety of sorafenib in patients in the Asia-Pacific region with advanced hepatocellular carcinoma: A phase III randomised, double-blind, placebo-controlled trial. Lancet Oncol. 2009, 10, 25-34. [CrossRef]

12. Schütte, K.; Tippelt, B.; Schulz, C.; Röhl, F.W.; Feneberg, A.; Seidensticker, R.; Arend, J.; Malfertheiner, P. Malnutrition is a prognostic factor in patients with hepatocellular carcinoma (HCC). Clin. Nutr. 2015, 34, 1122-1127. [CrossRef] [PubMed]

13. Rosenberg, I.H. Sarcopenia: Origins and clinical relevance. Clin. Geriatr. Med. 2011, 27, 337-339. [CrossRef] [PubMed]

14. Iritani, S.; Imai, K.; Takai, K.; Hanai, T.; Ideta, T.; Miyazaki, T.; Suetsugu, A.; Shiraki, M.; Shimizu, M.; Moriwaki, H. Skeletal muscle depletion is an independent prognostic factor for hepatocellular carcinoma. J. Gastroenterol. 2015, 50, 323-332. [CrossRef] [PubMed] 
15. Imai, K.; Takai, K.; Hanai, T.; Ideta, T.; Miyazaki, T.; Kochi, T.; Suetsugu, A.; Shiraki, M.; Shimizu, M. Skeletal muscle depletion predicts the prognosis of patients with hepatocellular carcinoma treated with sorafenib. Int. J. Mol. Sci. 2015, 16, 9612-9624. [CrossRef] [PubMed]

16. Hanai, T.; Shiraki, M.; Nishimura, K.; Ohnishi, S.; Imai, K.; Suetsugu, A.; Takai, K.; Shimizu, M.; Moriwaki, H. Sarcopenia impairs prognosis of patients with liver cirrhosis. Nutrition 2015, 31, 193-199. [CrossRef] [PubMed]

17. Hanai, T.; Shiraki, M.; Ohnishi, S.; Miyazaki, T.; Ideta, T.; Kochi, T.; Imai, K.; Suetsugu, A.; Takai, K.; Moriwaki, H.; et al. Rapid skeletal muscle wasting predicts worse survival in patients with liver cirrhosis. Hepatol. Res. 2016, 46, 743-751. [CrossRef] [PubMed]

18. Kobayashi, T.; Kawai, H.; Nakano, O.; Abe, S.; Kamimura, H.; Sakamaki, A.; Kamimura, K.; Tsuchiya, A.; Takamura, M.; Yamagiwa, S.; et al. Prognostic value of subcutaneous adipose tissue volume in hepatocellular carcinoma treated with transcatheter intra-arterial therapy. Cancer Manag. Res. 2018, 10, 2231-2239. [CrossRef]

19. Itoh, S.; Shirabe, K.; Matsumoto, Y.; Yoshiya, S.; Muto, J.; Harimoto, N.; Yamashita, Y.I.; Ikegami, T.; Yoshizumi, T.; Nishie, A.; et al. Effect of body composition on outcomes after hepatic resection for hepatocellular carcinoma. Ann. Surg. Oncol. 2014, 21, 3063-3068. [CrossRef]

20. Saeki, I.; Yamasaki, T.; Maeda, M.; Kawano, R.; Hisanaga, T.; Iwamoto, T.; Matsumoto, T.; Hidaka, I.; Ishikawa, T.; Takami, T.; et al. No muscle depletion with high visceral fat as a novel beneficial biomarker of sorafenib for hepatocellular carcinoma. Liver Cancer 2018, 7, 359-371. [CrossRef]

21. Nault, J.C.; Pigneur, F.; Nelson, A.C.; Costentin, C.; Tselikas, L.; Katsahian, S.; Diao, G.; Laurent, A.; Mallat, A.; Duvoux, C.; et al. Visceral fat area predicts survival in patients with advanced hepatocellular carcinoma treated with tyrosine kinase inhibitors. Dig. Liver Dis. 2015, 47, 869-876. [CrossRef] [PubMed]

22. Shimizu, M.; Tanaka, T.; Moriwaki, H. Obesity and hepatocellular carcinoma: Targeting obesity-related inflammation for chemoprevention of liver carcinogenesis. Semin. Immunopathol. 2013, 35, 191-202. [CrossRef] [PubMed]

23. Imai, K.; Takai, K.; Watanabe, S.; Hanai, T.; Suetsugu, A.; Shiraki, M.; Shimizu, M. Sarcopenia Impairs Prognosis of Patients with Hepatocellular Carcinoma: The Role of Liver Functional Reserve and Tumor-Related Factors in Loss of Skeletal Muscle Volume. Nutrients 2017, 9, 1054. [CrossRef] [PubMed]

24. Escudier, B.; Baracos, V.E.; Antoun, S.; Birdsell, L.; Sawyer, M.B.; Venner, P. Association of Skeletal Muscle Wasting with Treatment with Sorafenib in Patients with Advanced Renal Cell Carcinoma: Results from a Placebo-Controlled Study. J. Clin. Oncol. 2010, 28, 1054-1060. [CrossRef]

25. Arends, J.; Bachmann, P.; Baracos, V.; Barthelemy, N.; Bertz, H.; Bozzetti, F.; Fearon, K.; Hütterer, E.; Isenring, E.; Kaasa, S.; et al. ESPEN guidelines on nutrition in cancer patients. Clin. Nutr. 2017, 36, 11-48. [CrossRef] [PubMed]

26. Muscaritoli, M.; Anker, S.D.; Argilés, J.; Aversa, Z.; Bauer, J.M.; Biolo, G.; Boirie, Y.; Bosaeus, I.; Cederholm, T.; Costelli, P.; et al. Consensus definition of sarcopenia, cachexia and pre-cachexia: Joint document elaborated by Special Interest Groups (SIG) "cachexia-anorexia in chronic wasting diseases" and "nutrition in geriatrics". Clin. Nutr. 2010, 29, 154-159. [CrossRef] [PubMed]

27. Fearon, K.; Strasser, F.; Anker, S.D.; Bosaeus, I.; Bruera, E.; Fainsinger, R.L.; Jatoi, A.; Loprinzi, C.; MacDonald, N.; Mantovani, G.; et al. Definition and classification of cancer cachexia: An international consensus. Lancet Oncol. 2011, 12, 489-495. [CrossRef]

28. Argilés, J.M.; López-Soriano, F.J.; Busquets, S. Mechanisms to explain wasting of muscle and fat in cancer cachexia. Curr. Opin. Support. Palliat. Care 2007. [CrossRef] [PubMed]

29. Cederholm, T.; Barazzoni, R.; Austin, P.; Ballmer, P.; Biolo, G.; Bischoff, S.C.; Compher, C.; Correia, I.; Higashiguchi, T.; Holst, M.; et al. ESPEN guidelines on definitions and terminology of clinical nutrition. Clin. Nutr. 2017, 36, 49-64. [CrossRef] [PubMed]

30. Tran, T.T.; Yamamoto, Y.; Gesta, S.; Kahn, C.R. Beneficial Effects of Subcutaneous Fat Transplantation on Metabolism. Cell Metab. 2008, 7, 410-420. [CrossRef] [PubMed]

31. Murphy, R.A.; Wilke, M.S.; Perrine, M.; Pawlowicz, M.; Mourtzakis, M.; Lieffers, J.R.; Maneshgar, M.; Bruera, E.; Clandinin, M.T.; Baracos, V.E.; et al. Loss of adipose tissue and plasma phospholipids: Relationship to survival in advanced cancer patients. Clin. Nutr. 2010, 29, 482-487. [CrossRef] [PubMed] 
32. Nishikawa, H.; Shiraki, M.; Hiramatsu, A.; Moriya, K.; Hino, K.; Nishiguchi, S. Japan Society of Hepatology guidelines for sarcopenia in liver disease (1st edition): Recommendation from the working group for creation of sarcopenia assessment criteria. Hepatol. Res. 2016, 46, 951-963. [CrossRef] [PubMed]

33. Bruggeman, A.R.; Kamal, A.H.; LeBlanc, T.W.; Ma, J.D.; Baracos, V.E.; Roeland, E.J. Cancer Cachexia: Beyond Weight Loss. J. Oncol. Pract. 2016, 12, 1163-1171. [CrossRef] [PubMed]

34. Suzuki, Y.; Imai, K.; Takai, K.; Hanai, T.; Hayashi, H.; Naiki, T.; Nishigaki, Y.; Tomita, E.; Shimizu, M.; Moriwaki, H. Hepatocellular carcinoma patients with increased oxidative stress levels are prone to recurrence after curative treatment: A prospective case series study using the d-ROM test. J. Cancer Res. Clin. Oncol. 2013, 139, 845-852. [CrossRef] [PubMed]

35. Imai, K.; Takai, K.; Nishigaki, Y.; Shimizu, S.; Naiki, T.; Hayashi, H.; Uematsu, T.; Sugihara, J.; Tomita, E.; Shimizu, M.; et al. Insulin resistance raises the risk for recurrence of stage I hepatocellular carcinoma after curative radiofrequency ablation in hepatitis $C$ virus-positive patients: A prospective, case series study. Hepatol. Res. 2010, 40, 376-382. [CrossRef] [PubMed]

36. Watanabe, N.; Takai, K.; Imai, K.; Shimizu, M.; Naiki, T.; Nagaki, M.; Moriwaki, H. Increased levels of serum leptin are a risk factor for the recurrence of stage I/II hepatocellular carcinoma after curative treatment. J. Clin. Biochem. Nutr. 2011, 49, 153-158. [CrossRef] [PubMed]

37. Imai, K.; Takai, K.; Hanai, T.; Suetsugu, A.; Shiraki, M.; Shimizu, M. Homeostatic Model Assessment of Insulin Resistance for Predicting the Recurrence of Hepatocellular Carcinoma after Curative Treatment. Int. J. Mol. Sci. 2019, 20, 605. [CrossRef] [PubMed]

38. Moriwaki, H.; Shiraki, M.; Fukushima, H.; Shimizu, M.; Iwasa, J.; Naiki, T.; Nagaki, M. Long-term outcome of branched-chain amino acid treatment in patients with liver cirrhosis. Hepatol. Res. 2008, 38 (Suppl. 1), S102-S106. [CrossRef]

39. Imai, K.; Takai, K.; Maeda, T.; Watanabe, S.; Hanai, T.; Suetsugu, A.; Shiraki, M.; Shimizu, M. Increased visceral fat volume raises the risk for recurrence of hepatocellular carcinoma after curative treatment. Oncotarget 2018, 9, 14058-14067. [CrossRef]

40. Kudo, M.; Matsui, O.; Izumi, N.; Iijima, H.; Kadoya, M.; Imai, Y.; Okusaka, T.; Miyayama, S.; Tsuchiya, K.; Ueshima, K.; et al. JSH Consensus-Based Clinical Practice Guidelines for the Management of Hepatocellular Carcinoma: 2014 Update by the Liver Cancer Study Group of Japan. Liver Cancer 2014, 3, 458-468. [CrossRef]

41. Takayasu, K.; Furuse, J.; Nakamura, K.; Tanaka, M.; Kudo, M.; Ikai, I.; Kubo, S.; Sakamoto, M.; Makuuchi, M. Response Evaluation Criteria in Cancer of the Liver (RECICL) proposed by the Liver Cancer Study Group of Japan (2009 Revised Version). Hepatol. Res. 2010, 40, 686-692. [CrossRef]

42. Arizumi, T.; Ueshima, K.; Takeda, H.; Osaki, Y.; Takita, M.; Inoue, T.; Kitai, S.; Yada, N.; Hagiwara, S.; Minami, Y.; et al. Comparison of systems for assessment of post-therapeutic response to sorafenib for hepatocellular carcinoma. J. Gastroenterol. 2014, 49, 1578-1587. [CrossRef] [PubMed]

43. Mitsiopoulos, N.; Ross, R.; Gallagher, D.; Lyons, W.; Baumgartner, R.N.; Heymsfield, S.B. Cadaver validation of skeletal muscle measurement by magnetic resonance imaging and computerized tomography. J. Appl. Physiol. 2017, 85, 115-122. [CrossRef] [PubMed]

44. Yoshizumi, T.; Nakamura, T.; Yamane, M.; Waliul Islam, A.H.M.; Menju, M.; Yamasaki, K.; Arai, T.; Kotani, K.; Funahashi, T.; Yamashita, S.; et al. Abdominal Fat: Standardized Technique for Measurement at CT. Radiology 1999, 211, 283-286. [CrossRef]

(C) 2019 by the authors. Licensee MDPI, Basel, Switzerland. This article is an open access article distributed under the terms and conditions of the Creative Commons Attribution (CC BY) license (http://creativecommons.org/licenses/by/4.0/). 